\title{
Diabetes Mellitus at the Intersection of the COVID-19 Pandemic and the Opioid Crisis
}

\author{
Robert G Smith* \\ Shoe String Podiatry Ormond Beach, Florida, North America, USA \\ ^Corresponding author: Robert G Smith, Shoe String Podiatry 723 Lucerne Circle Ormond Beach, Florida 32174, USA; Tel: +13866739933; E-mail: asamaan@cfl.rr.com
}

Received: June 06, 2020; Accepted: June 14, 2020; Published: July 24, 2020

\section{Introduction}

Boslet et al. used a secondary data analysis of the universe of drug overdoses in 1999-2016 obtained from the National Center for Health Statistics Detailed Multiple Cause of Death records to demonstrate that the number of deaths attributed to opioid-related overdoses could be 28 percent higher than first reported due to incomplete death records [1]. This discrepancy was more pronounced in several states, to include Alabama, Mississippi, Pennsylvania, Louisiana, and Indiana, where the estimated number of deaths more than doubles obscuring the scope of the opioid crisis and potentially affecting programs and funding intended to confront the epidemic [1]. Logistic regression and random forest models were performed to determine contributing causes substantially that improved predictive accuracy, while including county characteristics. Using a superior prediction model, they found that $71.8 \%$ of unclassified drug overdoses in 19992016 involved opioids, and thus translating into 99160 additional opioid-related deaths, or approximately $28 \%$ more than previously reported [1]. It is hoped a physician relies on census data as essential tools for understanding the importance of place-level characteristics on opioid mortality. Opioid mortality rates overall are higher in counties characterized by more economic disadvantage, more bluecollar and service employment, and higher opioid-prescribing rates [2]. Medical literature have reported that high rates of prescription opioid overdoses and overdoses involving both prescription and synthetic opioids cluster in more economically disadvantaged counties with larger concentrations of service industry workers [2]. Further, Monnat et al. suggest national policies to combat the opioid and larger drug crises, emphasis should be on developing locally and regionally tailored interventions, with attention to place-based structural economic and social characteristics [2].

An appreciation as of April 2020, the United States now has 22 million unemployed, wiping out a decade of job gains. Woolhandler and Himmelstein assert with jobs and health insurance coverage disappearing as the COVID-19 pandemic rages, states that have declined to expand Medicaid should urgently reconsider [3]. Moreover, state tax revenues are plunging due to shelter in place orders and initiatives in place to have only essential workers to attend their place of business. The foreboding realization is that only the federal government can address this financial impending crisis [3]. Secondly these authors state health care coverage losses are likely to be steepest in states that have turned down the Patient Protection and Affordable
Care Act's Medicaid expansion [3]. Additionally, in expansion states, the share of persons who have lost or left a job who lacked coverage was $22.1 \%$ versus $8.3 \%$ for employed persons-a difference of 13.8 percentage points [3]. These authors acknowledge that although the COVID-19 crisis demands urgent action, it also exposes the carelessness of tying health insurance to employment and the need for more thoroughgoing reform [3]. It is hoped that the issue of families who face the dual disaster of job loss and health insurance loss and who may suffer from opioid use disorder will be among the foremost issues on the legislative branch of the United States' agenda. Haffajee et al., report opioid overdose deaths in the United States continue to increase, reflecting a growing need to treat those with opioid use disorder [4]. Acknowledging that fading economic opportunity has been hypothesized to be an important factor associated with the United States opioid overdose crisis. Automotive assembly plant closures are culturally significant events that substantially erode local economic opportunities [5]. Moreover, Venkataramani et al. explores and investigates a community's economy has on opioid overdose mortality. Their primary outcome was the county-level age-adjusted opioid overdose mortality rate [5]. Their secondary outcomes included the overall drug overdose mortality rate and prescription vs. illicit drug overdose mortality rates [5]. They discovered that from 1999 to 2016, automotive assembly plant closures were associated with increases in opioid overdose mortality [5]. These findings highlight the potential importance of eroding economic opportunity as a factor in the United States opioid overdose crisis [5]. Finally, Langbeer et al. concluded univariate, opioid-related morality was positively correlated with tobacco use, being non-Hispanic Caucasian individual, living in a rural area, obesity, being 65-years of age or older, and a higher rate of unemployment [6].

Gautam et al. reported that diabetes mellitus has well known costly complications but wanted to show through a retrospective model that costs of care for chronic pain treated with opioid analgesic medications would also be substantial [7]. They found that higher costs of care for opioid-treated patients appeared for all types of services and likely reflects multiple factors including morbidity from the underlying cause of pain, care and complications related to opioid use, and poorer control of diabetes as found in other investigations [7]. Schiemsky et al. reported a case of hypoglycemia caused by inappropriate stimulation of insulin secretion in a patient intoxicated with tramadol [8]. They further explain the sudden hypokalemia was caused by a massive intracellular shift of potassium in response to 
the hyperinsulinemia, triggered by the intravenous administration of glucose [8]. Makunts et al. analyzed over twelve million reports from United States Food and Drug Administration Adverse Event Reporting System to provide evidence of increased propensity for hypoglycemia in patients taking tramadol when compared to patients taking other opioids, serotonin-norepinephrine reuptake inhibitors, and drugs affecting (NMDAR) activity [9]. They identified that both tramadol and methadone behave similarly to tramadol and has an association with hypoglycemia [9]. These findings accentuates the need for monitoring of a patient's blood glucose given the overlap of the opioid crisis and COVID-19 pandemic.

As people across the United States and the rest of the world contends with coronavirus disease 2019 (COVID-19), the medical community to include podiatric physicians should realize the possibility that COVID-19 infection could hit some populations with Substance Use Disorders (SUDs) particularly hard [10]. The coronavirus that causes COVID-19 attacks the lungs and could be an especially serious threat to those patients who smoke tobacco, marijuana or who vape. People with Opioid Use Disorder (OUD) and methamphetamine use disorder may also be vulnerable due to those drugs' effects on respiratory and pulmonary health [10]. Additionally, patients with a substance use disorder are more likely to experience homelessness or incarceration than those in the general population, and these circumstances pose unique challenges regarding transmission of the virus that causes COVID-19. All these possibilities should be a focus of active surveillance as we work to understand this emerging health threat [10].

According to Volkow those persons who are isolated and stressed as much of the population is during the COVID-19 pandemic frequently turn to substances to alleviate their negative feelings [11]. Those in substance recovery will face stresses and heightened urges to use substances and will be at greatly increased risk for relapse [11]. Further, vulnerable populations those who smoke or vape, use opioids, or have a Substance Use Disorder (SUD) may have direct challenges to respiratory health, those with SUD may be especially susceptible to infection by the virus that causes COVID-19 and associated complications [11]. Impediments to delivering care to this population, persons with SUD who develop COVID-19 may find it harder to get healthcare [11]. Those in recovery will also be uniquely challenged by social distancing measures [11]. Lastly, a risk for severe COVID-19 and death escalates with older age but is also concentrated among those who are immunocompromised or have underlying health conditions, including diabetes, cancer, and heart and respiratory diseases [11].

Mukherjee and El-Bassel report that people with opioid and other substance use disorders are disproportionately incarcerated, and recently released prisoners are ten times more likely to become homeless [12]. During the COVID-19 pandemic coupled without adequate planning, de-carceration efforts in may move people with Opioid Use Disorder from one at risk environment to another at risk environment [12]. Upon release, the risks associated with COVID-19, as well as HIV, viral hepatitis, Tuberculosis, overdose and homelessness that often accompany incarceration must be considered [12].
It is an accepted fact that not only does COVID-19 make addiction services harder to access but people who use drugs may be at higher risk of infection given the dangerous overlap between addiction, incarceration, and the rapid spread of infections within confined spaces. Community campaigns to get nonviolent drug offenders released during this pandemic may not be sufficient to avoid incarcerated persons from becoming infected with COVID-19. A prisoner re-entry into regular society is difficult and dangerous from a health perspective, even during normal times. As the economy collapses, shelters and food banks have been overwhelmed, with already limited resources stretched thin on all levels in many communities.

\section{Opioids and Increase of Infections}

Schwetz et al. rely on clinical evidence to assert in their commentary that the rise in Opioid Use Disorder (OUD), bolstered by injection opioid use, conveys numerous downstream consequences and is fueling a surge in infectious diseases, such as Human Immunodeficiency Virus (HIV) infection with or without AIDS, the viral hepatitides, infective endocarditis, pneumonia, and skin and soft-tissue infections [13,14]. Further, Schwetz et al. note the increasing infection rates and demographic trends of bacterial and fungal infections appear to mirror trends observed with the opioid epidemic $[13,15]$. They cite the example of the rate of methicillinresistant Staphylococcus aureus infections among people who inject drugs more than doubled between the years of 2011 and 2016 [16]. Additionally, they assert the growing evidence has shown that certain opioids to include both morphine and fentanyl that have putative effects on both the innate and adaptive immune systems, dependent on drug dosage and duration of delivery [13]. Finally, these authors concluded using published data that the growing trend of infectious diseases emerging across the United States in areas with high rates of opioid use has created a significant combined impact on morbidity and mortality [13].

Wiese et al, conducted a retrospective cohort study to investigate long-acting opioid use and the risk of serious infections [17]. They used multivariable Poisson regression models to calculate adjusted incidence rate ratios and $95 \%$ confidence intervals to compare the infection risk among patients using long-acting opioids with known immunosuppressive properties (morphine, fentanyl, methadone) to the infection risk among patients using long-acting opioids without known immunosuppressive properties (oxycodone, oxymorphone, tramadol) accounting for demographics, opioid dose, comorbidities and pain conditions, medication use, frailty indicators, and healthcare encounter history using exposure propensity scores [17]. Moreover, they compared users of individual long-acting opioids to long-acting morphine users that considered the prototypical immunosuppressive opioid [17]. They determined the risk of serious infections among long-acting opioid users varies by opioid type [17]. They suggest that providers should carefully consider the risk of serious infections when making pain management decisions [17]. Karagiannis et al. acknowledge that chronic opioid usage not only causes addiction behavior through the central nervous system, but also modulates the peripheral immune system [18]. Further they ask the question 
how do opioids impact the immune system and recognize it is still barely characterized systematically [18]. In order to understand the immune modulatory effect of opioids in an unbiased way, here they perform single-cell RNA sequencing (scRNA-seq) of peripheral blood mononuclear cells from opioid-dependent individuals and controls to show that chronic opioid usage evokes widespread suppression of antiviral gene program in naive monocytes, as well as in multiple immune cell types upon stimulation with the pathogen component lipopolysaccharide [18]. Furthermore, scRNA-seq reveals the same phenomenon after a short in vitro morphine treatment was discovered [18]. Their findings indicate that both acute and chronic opioid exposure may be harmful to our immune system by suppressing the antiviral gene program [18]. Lastly, their results suggest that further characterization of the immune modulatory effects of opioid is critical to ensure the safety of clinical opioids [18]. These results are of upmost importance in understanding the use of opioids in patients with diabetes mellitus during the current COVID-19 pandemic.

\section{Diabetes Mellitus and COVID-19 Pandemic}

In the United States, 34.2 million or $10.5 \%$ of the total population have diabetes mellitus [19]. Among those aged 65 years or older, a population at higher risk for death from COVID-19, 26.8\% has diabetes mellitus [19]. Muniyappa and Gubbi summarize that individuals with diabetes mellitus, hypertension, and severe obesity (BMI $40 \mathrm{~kg} / \mathrm{m}^{2}$ ) are more likely to be infected and are at a higher risk for complications and death from COVID-19 [20]. Given, consideration to the high prevalence of cardiovascular disease (CVD), obesity, and hypertension in patients with diabetes mellitus, according to Muniyappa and Gubbi it is unknown whether diabetes mellitus independently contributes to the increased risk of being infective with COVID-19 [20]. However, plasma glucose levels and diabetes mellitus are independent predictors for mortality and morbidity in patients with SARS [21]. Potential mechanisms that may increase the susceptibility for COVID-19 in patients with diabetes mellitus include: 1) higher affinity cellular binding and efficient virus entry, 2) decreased viral clearance, 3) diminished T cell function, 4) increased susceptibility to hyperinflammation and cytokine storm syndrome, and 5) presence of cardiovascular disease [20]. Additionally, diabetes mellitus inhibits neutrophil chemotaxis, phagocytosis, and intracellular killing of microbes. Impairments in adaptive immunity characterized by an initial delay in the activation of Th1 cell-mediated immunity and a late hyperinflammatory response is often observed in patients with diabetes [22].

Another point explained by Hussain et al. is that the clinical spectrum of COVID-19 is heterogeneous, ranging from mild flu-like symptoms to acute respiratory distress syndrome, multiple organ failure and death [23]. Older age, diabetes and other comorbidities are reported as significant predictors of morbidity and mortality [23]. Chronic inflammation, increased coagulation activity, immune response impairment, and potential direct pancreatic damage by SARS-CoV-2 might be among the underlying mechanisms of the association between diabetes and COVID-19 [23].

Finally, Bode et al. proposed the concept that diabetes and/or uncontrolled hyperglycemia occur frequently among hospitalized patients with COVID-19 and are associated with worse outcomes [24]. To investigate this concept they performed a retrospective observational study of laboratory-confirmed COVID-19 adults evaluated glycemic and clinical outcomes in patients with and without diabetes and/or acutely uncontrolled hyperglycemia who were hospitalized [24]. Among hospitalized patients with COVID-19, diabetes and/or uncontrolled hyperglycemia occurred frequently [24]. These COVID-19 patients with diabetes and/or uncontrolled hyperglycemia had a longer length of stay and markedly higher mortality than patients without diabetes or uncontrolled hyperglycemia [24]. These investigators observed that patients with uncontrolled hyperglycemia had a particularly high mortality rate [24]. The physician can appreciate the potential effects of drug treatment options being used in the management of COVID-19 on glucose and lipid profiles summarized in Table 1 [25].

Table 1: Summary of the potential effects of Medications options being used in the management of COVID-19 on glucose and lipid profiles.

\begin{tabular}{|c|c|c|c|c|}
\hline Medications & Mechanism of action on COVID-19 & Effect on glucose profile & Effect on lipid profile & \\
\hline Corticosteroids & Anti-inflammatory, blocks cytokine storm & Hyperglycemia & Dyslipidemia & $\uparrow$ \\
\hline Lopinavir/Ritonavir & $\begin{array}{l}\text { Protease inhibitors, blocks viral cellular } \\
\text { entry }\end{array}$ & $\begin{array}{l}\text { Hyperglycemia } \\
\text { Lipodystrophy }\end{array}$ & Dyslipidemia & $\uparrow$ \\
\hline Darunavir/Cobicistat & $\begin{array}{l}\text { Protease inhibitors, blocks viral cellular } \\
\text { entry }\end{array}$ & $\begin{array}{l}\text { Hyperglycemia } \\
\text { Lipodystrophy }\end{array}$ & Dyslipidemia & $\uparrow$ \\
\hline Remdesivir & $\begin{array}{l}\text { Adenosine analogue, inhibits viral } \\
\text { replication }\end{array}$ & Increased blood glucose & Increased blood lipids & \\
\hline Interferons (b1) & $\begin{array}{l}\text { Cytokine, stimulate innate antiviral } \\
\text { immunity }\end{array}$ & $\begin{array}{l}\text { Can lead to autoimmune b-cell damage thereby, } \\
\text { precipitating or worsening diabetes mellitus }\end{array}$ & Dyslipidemia & $\uparrow$ \\
\hline Chloroquine/Hydroxychloroquine & $\begin{array}{l}\text { Increases host cell endosomal } \mathrm{pH} \text {, prevents } \\
\text { viral entry and immunomodulator }\end{array}$ & $\begin{array}{l}\text { Improves glucose profile and } \mathrm{HbAlc} \text { in people with Type } \\
2 \text { Diabetes Mellitus }\end{array}$ & $\begin{array}{l}\text { Improves lipid profile in people with } \\
\text { Type } 2 \text { Diabetes Mellitus }\end{array}$ & \\
\hline Azithromycin & Macrolide antibiotic & Risk of dysglycemia in people with diabetes mellitus & $\begin{array}{l}\text { No robust data Being an enzyme } \\
\text { inhibitor, may prolong half-life of statins }\end{array}$ & \\
\hline Camostat mesilate & $\begin{array}{l}\text { Protease inhibitors, blocks viral maturation } \\
\text { and entry into cells }\end{array}$ & $\begin{array}{l}\text { Found to lower blood glucose levels in insulin-treated } \\
\text { patients with diabetes mellitus }\end{array}$ & Not known & \\
\hline Tocilizumab & $\begin{array}{l}\text { Monoclonal antibody against IL-6, blocks } \\
\text { cytokine storm }\end{array}$ & $\begin{array}{l}\text { Improves glucose profile and reduces HbAlc in people } \\
\text { with rheumatoid arthritis and diabetes mellitus }\end{array}$ & $\begin{array}{l}\text { Alters lipid profile in people with } \\
\text { rheumatoid arthritis }\end{array}$ & \\
\hline Convalescent plasma & Provides anti-SARS-CoV-2 antibodies & Not known & Not known & \\
\hline
\end{tabular}


Table 2: Comparison List of the Typical Symptoms of Covid-19 Infection and Opioid Withdrawal Symptoms.

\begin{tabular}{|l|c|c|}
\hline $\begin{array}{l}\text { Covid-19 Infection Symptoms } \\
{[\mathbf{2 5}]}\end{array}$ & $\begin{array}{c}\text { Opioid Withdrawal Symptoms [26] } \\
\text { Symptoms appear 72 hours after last dose }\end{array}$ \\
\hline Fever & $87.90 \%$ & Fever \\
\hline Dry Cough & $67.70 \%$ & Chills \\
\hline Fatigue & $38.10 \%$ & Body Aches \\
\hline Sputum Production & & Diarrhea \\
\hline Shortness of Breath & & Insomnia \\
\hline Myalgia-Arthralgia & $14.80 \%$ & Muscle Pain \\
\hline Sore Throat & $13.90 \%$ & Nausea \\
\hline Headache & $13.60 \%$ & Dilated Pupils \\
\hline Chills & $11.40 \%$ & \\
\hline Nausea-Vomiting & $5 \%$ & \\
\hline Nasal Congestion & $4.80 \%$ & \\
\hline Diarrhea & $3.70 \%$ & \\
\hline
\end{tabular}

Source: National Institute of Drug Abuse.

Source: Report of the WHO China.

Joint Mission on Coromavirus Disease 2019

\section{Strategies for Managing Chronic Pain}

The COVID-19 public health crisis has strained health care systems, creating an enigma for patients, pain medicine practitioners, hospital leaders, and regulatory officials [26]. Pain management providers rely on infection control precautions form a backbone of interventionalbased and some alternative medicine to include: acupuncture, handson therapies such as massage and manual therapy practices [26]. These precautions are even more important during a pandemic where the potential exists for viral shedding from asymptomatic patients and disease transmission [26]. The clinicians need to acknowledge that many patients who would be seen in for chronic pain issues during the COVID-19 pandemic are in higher risk groups and full consideration should be given to minimizing patients congregating in a waiting room. Specialists should familiarize themselves to the new Health Human Services and Centers for Medicare and Medicaid Services relaxations on telemedicine provide a method for new patient and established patient visits [26]. In patients on opioids who may have run out of medications because of logistical obstacles or overuse, assessment of withdrawal signs can be challenging during remote visits. These symptoms such as diarrhea, rhinorrhea, abdominal pain and chills can be garnered from patient interviews, but may be difficult to corroborate [26]. On the other hand, some physical signs indicative of opioid withdrawal, particularly if prominent, can be observed remotely such as agitation, diaphoresis, piloerection, and possibly even pupillary size [26]. Monitoring patients for an elevated heart or pulse rate, which is a classic sign of opioid withdrawal, can sometimes be done by reliable patients or their caregivers [26]. The salient point that typical symptoms of COVID-19 overlap the typical symptoms of opioid withdrawal has to be realized by the podiatric physician so that a correct diagnosis can be determined and a negative outcome can be avoided. A list of the typical symptoms of COVID-19 infection along with the presenting typical symptoms of opioid withdrawal are presented in Table 2 so a comparison can be appreciated [27,28].

\section{Conclusion}

First, the negative economic impact of the COVID-19 pandemic and how it exacerbates the opioid crisis in America was presented.
Then certain factors of patients with substance abuse disorders and how they are disadvantaged by excessive and prolonged isolation and social distancing is presented. The effects of opioid use and addiction as well as the pathology Diabetes Mellitus on pulmonary and immune function that effect a patient's response COVID-19 was presented. Lastly, strategies for managing chronic pain and access to medical care were presented. It is hoped the physician can appreciate the over shadowed area at the intersection of the COVID-19 Pandemic and the Opioid Crisis.

\section{References}

1. Boslett AJ, Denham A, Hill EL (2020) Using contributing causes of death improves prediction of opioid involvement in unclassified drug overdoses in US death records. Addiction 115: 1308-1317.

2. Monnat SM, Peters DJ, Berg MT, Hochstetler A (2019) Using Census Data to Understand County-Level Differences in Overall Drug Mortality and Opioid-Related Mortality by Opioid Type. Am J Public Health 109: 1084-1091. [crossref]

3. Woolhandler S, Himmelstein DU (2020) Intersecting US. Epidemics: COVID-19 and Lack of Health Insurance [published online ahead of print, 2020 Apr 7]. Ann Intern Med 173: 63-64. [crossref]

4. Haffajee RL, Lin LA, Bohnert ASB, Goldstick JE (2019) Characteristics of US Counties with High Opioid Overdose Mortality and Low Capacity to Deliver Medications for Opioid Use Disorder. JAMA Netw Open 2: e196373. [crossref]

5. Venkataramani AS, Bair EF, O’Brien RL, Tsai AC (2019) Association between Automotive Assembly Plant Closures and Opioid Overdose Mortality in the United States: A Difference-in-Differences Analysis. JAMA Intern Med 180: 254-262. [crossref]

6. Langabeer JR, Chambers KA, Cardenas-Turanzas M, Champagne-Langabeer $\mathrm{T}$ (2020) County-level factors underlying opioid mortality in the United States [published online ahead of print, 2020 Mar 18]. Subst Abus 1-7.

7. Gautam S, Franzini L, Mikhail OI, Chan W, Turner BJ (2016) Novel Measure of Opioid Dose and Costs of Care for Diabetes Mellitus: Opioid Dose and Health Care Costs. J Pain 17: 319-327. [crossref]

8. Schiemsky T, Vundelinckx G, Croes K, Penders J, Desmet K, et al. (2020) An unconscious man with profound drug-induced hypoglycaemia. Biochem Med (Zagreb) 30: 010802. [crossref]

9. Makunts TUA, Atayee RS, Abagyan R (2019) Retrospective analysis reveals significant association of hypoglycemia with tramadol and methadone in contrast to other opioids. Sci Rep 9: 12490. [crossref]

10. COVID-19: Potential Implications for Individuals with Substance Use Disorders. National Institute of Drug Abuse. Nora’s Blog Volkow N. 2020.

11. Volkow ND (2020) Collision of the COVID-19 and Addiction Epidemics [published online ahead of print, 2020 Apr 2]. Ann Intern Med 173: 61-62. [crossref]

12. Mukherjee TI, El-Bassel N (2020) The perfect storm: COVID-19, mass incarceration and the opioid epidemic [published online ahead of print, 2020 Jun 11]. Int J Drug Policy 102819.

13. Schwetz TA, Calder T, Rosenthal E, Kattakuzhy S, Fauci AS (2019) Opioids, and Infectious Diseases: A Converging Public Health Crisis. J Infect Dis 220: 346-349. [crossref]

14. Wiese AD, Griffin MR, Schaffner W, Stein CM, Greevy RA, et al. (2018) Opioid Analgesic Use and Risk for Invasive Pneumococcal Diseases: A Nested Case-Control Study. Ann Intern Med 168: 396-404. [crossref]

15. Ronan MV, Herzig SJ (2016) Hospitalizations related to opioid abuse/dependence and associated serious infections increased sharply, 2002-12. Health Aff (Millwood) 35: 832-837. [crossref]

16. Jackson KA, Bohm MK, Brooks JT, Asher A, Nadle J, et al. (2018) Invasive methicillinresistant Staphylococcus aureus infections among persons who inject drugs- six sites, 2005-2016. MMWR Morb Mortal Wkly Rep 67: 625-628. [crossref] 
17. Wiese AD, Griffin MR, Schaffner W, Stein CM, Greevy RA, et al. (2019) Long-acting Opioid Use and the Risk of Serious Infections: A Retrospective Cohort Study. Clin Infect Dis 68: 1862-1869. [crossref]

18. Karagiannis TT, Cleary JP, Gok B, et al. (2020) Single cell transcriptomics reveals opioid usage evokes widespread suppression of antiviral gene program. Nat Commun 11: 2611 .

19. Centers for Disease Control and Prevention. National Diabetes Statistics Report, 2020. Atlanta, GA: Centers for Disease Control and Prevention, US Department of Health and Human Services. 2020.

20. Muniyappa R, Gubbi S (2020) COVID-19 pandemic, coronaviruses, and diabetes mellitus. Am J Physiol Endocrinol Metab 318: E736-E741. [crossref]

21. Yang JK, Feng Y, Yuan MY, Yuan SY, Fu HJ, et al. (2006) Plasma glucose levels and diabetes are independent predictors for mortality and morbidity in patients with SARS. Diabet Med 23: 623-628. [crossref]

22. Hodgson K, Morris J, Bridson T, Govan B, Rush C, et al. (2015) Immunological mechanisms contributing to the double burden of diabetes and intracellular bacterial infections. Immunology 144: 171-185. [crossref]
23. Hussain A, Bhowmik B, do Vale Moreira NC (2020) COVID-19 and diabetes: Knowledge in progress. Diabetes Res Clin Pract 162: 108142. [crossref]

24. Bode B, Garrett V, Messler J, Raymie McF, Jennifer C, et al. (2020) Glycemic Characteristics and Clinical Outcomes of COVID-19 Patients Hospitalized in the United States. J Diabetes Science and Technology 1-9. [crossref]

25. Pal R, Bhadada SK (2020) COVID-19 and diabetes mellitus: An unholy interaction of two pandemics. Diabetes \& Metabolic Syndrome: Clinical Research \& Reviews 14: 513-517. [crossref]

26. Cohen SP, Baber ZB, Buvanendran A, McLean BC, Chen Y, et al. (2020) Pain Management Best Practices from Multispecialty Organizations during the COVID-19 Pandemic and Public Health Crises [published online ahead of print, 2020 Apr 7]. Pain Med 21: 1331-1346. [crossref]

27. Aylward B, Liang W (2020) The WHO-China joint mission of 25 national and international experts was held from 16-24.

28. Drug Withdrawal Symptoms. Accessed June 28, 2020. 